\title{
The Effects of Iron Chelators on the Colonial Morphology of Neisseria gonorrhoeae
}

\author{
By TOLU O. ODUGBEMI AND SALEEM HAFIZ \\ Department of Medical Microbiology, \\ University of Sheffield Medical School, \\ Beech Hill Road, Sheffield SIO $2 R X$
}

(Received I 3 July I977; revised 26 September I977)

\section{INTRODUCTION}

There has recently been considerable interest in the role of iron in microbial pathogenicity. Bullen, Rogers \& Griffiths (1974) have reviewed the importance of iron compounds in enhancing the virulence of many bacteria. However, the gonococcus was not amongst those mentioned. Kellogg et al. (1963) showed that adding iron to medium improved the growth of gonococci. They also described four characteristic colonial types of gonococci which they were able to relate to infectivity for volunteers. Thus types I and 2 were virulent and types 3 and 4 non-virulent. Jephcott \& Reyn (I97I) confirmed these observations and added a further colonial type which they called type 5 and regarded as non-pathogenic.

Payne \& Finkelstein (1975) showed that iron compounds added to inocula of the relatively avirulent colonial types 3 and 4 increased their lethality for chick embryos on intravenous inoculation. They did not attribute the increased lethality in the presence of iron to a reversion to pathogenic colonial types but considered the effect to be host mediated. Hafiz, McEntegart \& Jephcott (1977) found that a high concentration of iron, in the form of ferric citrate incorporated into liquid media, caused reversion of nonpathogenic type 4 colonies of gonococci (previously thought to be very stable and irreversible in vitro) to pathogenic type $\mathrm{I}$. Iron, though an important component of the media in which the reversion was studied, could not be considered in isolation without looking at the possible effects of the other components, especially citrate which is known to chelate iron. Cole (1952) reported that metal chelators added to culture media suppressed colonial variation of smooth, pathogenic Brucella abortus to the rough non-pathogenic variant. The effects of iron chelators on the colonial morphology of the gonococcus have not to our knowledge been reported before. This study was undertaken to determine the role of iron and the possible effects of iron chelators on the colonial morphology of the gonococcus.

\section{METHODS}

Medium. The basic medium was the liquid medium (ANM) of Hafiz \& McEntegart (1976) consisting of ( $\mathrm{g}$ per 1 distilled water): proteose peptone (Difco), I5; soluble starch, I; NaCl, $5 ; \mathrm{K}_{2} \mathrm{HPO}_{4}, 4 ; \mathrm{KH}_{2} \mathrm{PO}_{4}$,

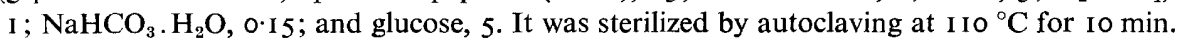

Strains. The strains of gonococci used were: F62 (originally isolated in Kellogg's laboratory); freshly isolated local strains GC338, GC4I and GCI7; and the new penicillinase-producing strain ' $\mathrm{R}$ ' (kindly provided by Dr G. C. Turner, Public Health Laboratory Services, Liverpool).

Selection and study of colonial types. Types $\mathrm{I}$ and 4 were selected using the special lighting system of Jephcott \& Reyn (1971). The selected colonies were emulsified in phosphate-buffered saline pH $7{ }^{\circ}$, mixed thoroughly in Vortex Junior mixer (Scientific Industries), and $0.04 \mathrm{ml}$, containing approximately $10^{6}$ colony-forming units (c.f.u.) $\mathrm{ml}^{-1}$, was inoculated into $15 \mathrm{ml}$ of liquid media. The liquid cultures in $30 \mathrm{ml}$ screw-top bottles were incubated at 35 to $36{ }^{\circ} \mathrm{C}$ in a humidified atmosphere of air plus $10 \%(\mathrm{v} / \mathrm{v}) \mathrm{CO}_{2}$, as were the solid cultures, to ensure the same temperature conditions for both cultures. The colonial morphology was studied daily by sub-inoculating on GC agar (Difco) plus $2 \%$ defined supplement (Kellogg et al., 1963). The colonies were confirmed as gonococci by their oxidase and fermentation reactions and their typical bright fluorescence when treated with an antigonococcal conjugate (Difco). 


\section{Table I. Effect of iron chelators, L-glutamic acid and ferric nitrate on the} colonial morphology of $N$. gonorrhoeae $\mathrm{F} 62$, types $\mathrm{I}$ and 4

Type I colonies were determined periodically by inoculation of cultures in liquid media on to solid medium. Results are expressed as the percentages of type 1 colonies present.

Type 4 inoculum

\begin{tabular}{|c|c|c|c|c|}
\hline $\begin{array}{c}\text { Addition (per l } \\
\text { Time of growth } \\
\text { (days)... }\end{array}$ & I & 2 & 3 & 4 \\
\hline None & 0 & 0 & 0 & 0 \\
\hline L-Glu, $2.5 \mathrm{~g}$ & 50 & 80 & 5 & 5 \\
\hline $\mathrm{Fe}\left(\mathrm{NO}_{3}\right)_{3}, \mathrm{Ig}$ & 0 & o & 0 & 0 \\
\hline Na citrate, $2.94 \mathrm{~g}$ & 0 & 0 & 0 & 20 \\
\hline Desferal, io mg & 0 & o & o & o \\
\hline Desferal, $5 \mathrm{mg}+\mathrm{Fe}\left(\mathrm{NO}_{3}\right)_{3}, 0.5 \mathrm{~g}$ & 10 & 5 & o & 5 \\
\hline None & 0 & 0 & 0 & o \\
\hline L-Glu, $2.5 \mathrm{~g}$ & 50 & 80 & 5 & 5 \\
\hline NTA, $0.19 \mathrm{~g}+\mathrm{L}-\mathrm{Glu}, 2.5 \mathrm{~g}$ & 0 & 5 & 4 & 20 \\
\hline NTA, $0.19 \mathrm{~g}$ & 15 & 5 & 26 & 50 \\
\hline NTA, $0.38 \mathrm{~g}$ & 40 & 0 & 28 & 80 \\
\hline $\mathrm{NTA}, 0.19 \mathrm{~g}+\mathrm{Fe}\left(\mathrm{NO}_{3}\right)_{3}, 1 \mathrm{~g}$ & 0 & o & 0 & 0 \\
\hline None & 0 & 0 & 0 & 0 \\
\hline L-Glu, I $25 \mathrm{~g}$ & 5 & 30 & 20 & 25 \\
\hline L-Glu, $2.5 \mathrm{~g}$ & 20 & 60 & 5 & 40 \\
\hline $\mathrm{L}-$ Glu, $5 \mathrm{~g}$ & 5 & 30 & 5 & 40 \\
\hline $\mathrm{L}-\mathrm{Glu}, \mathrm{g} \mathrm{g}$ & 4 & 20 & 5 & IO \\
\hline Ferric ammonium citrate, I $\mathrm{g}$ & 4 & 45 & 45 & 60 \\
\hline
\end{tabular}

Type $\mathrm{I}$ inoculum

$\begin{array}{rrrrr}\text { I } & 2 & 3 & 4 & 5 \\ 20 & 0 & 0 & 3 & 5 \\ 80 & 5 & 5 & 5 & 4 \\ 0 & 0 & 0 & 0 & 5 \\ 60 & 0 & 5 & 20 & 30 \\ 0 & 0 & 0 & 0 & 0 \\ 60 & 5 & 5 & 5 & 3 \\ 20 & 0 & 0 & 3 & 3 \\ 80 & 3 & 5 & 5 & 5 \\ 5 & 60 & 80 & 60 & 60 \\ 25 & 80 & 40 & 80 & 80 \\ 4 & 80 & 80 & 80 & 60 \\ 3 & 0 & 3 & 0 & 0 \\ 20 & 0 & 0 & 3 & 5 \\ 99 & 25 & 10 & 40 & 30 \\ 99 & 35 & 25 & 50 & 30 \\ 99 & 30 & 35 & 90 & 40 \\ 99 & 5 & 5 & 20 & 10 \\ 99 & 40 & 35 & 25 & 10\end{array}$

L-Glu, L-Glutamic acid; Desferal, deferrioxamine B; NTA, nitrilotriacetic acid.

\section{RESULTS}

The five strains of gonococci responded similarly to various chelating agents, glutamic acid and ferric nitrate. As an example, the results obtained for a series of six groups of experiments with Neisseria gonorrhoeae F62 types I and 4 are detailed in Table I. Of the substances examined, only nitrilotriacetic acid (NTA), ferric ammonium citrate and Lglutamic acid, particularly at the intermediate concentrations tested, brought about reversion of type 4 to type 1 . In other experiments, L-glutamic acid above $5 \mathrm{~g} \mathrm{l}^{-1}$ either supported very good growth of type 4 gonococci, inhibited growth or caused occasional but delayed reversion to type I until after 5 days. Interestingly, whilst reversion from type 4 to type I with NTA was delayed for 3 days and with ferric ammonium citrate for 2 days, L-glutamic acid had an almost immediate effect. However, with both NTA and ferric ammonium citrate the reverted colonies persisted on subsequent sub-inoculation whereas with Lglutamic acid they disappeared on further subculture.

When the same experiments were repeated with type I colonies as inoculum, NTA, ferric ammonium citrate and L-glutamic acid again were the most effective in preventing the reversion of type I cultures to predominantly type 4 (Table I). Although the effects of all three compounds were prolonged, those of NTA and ferric ammonium citrate were greater than that of L-glutamic acid.

The other two chelators, sodium citrate and Desferal plus $\mathrm{Fe}^{3+}$, exhibited a marginal effect in the two series of experiments. Desferal or $\mathrm{Fe}^{3+}$ alone were ineffective.

\section{DISCUSSION}

The present study supports the recent findings that iron is essential for reversion of gonococci type 4 to type I (Hafiz et al., 1977). The results also show that iron chelators, particularly nitrilotriacetate and citrate, affect colonial morphology of gonococci in liquid 
medium. The finding that $\mathrm{L}$-glutamic acid at $2.5 \mathrm{~g}^{-1}$ could cause reversion of gonococci type 4 to type I could not be explained. However, amino acids generally are weak chelators (Hutner, 1972) and the effect of glutamate may not be unconnected with glutamine being a component of the 'defined supplement' used to enhance growth of the gonococcus (Kellogg et al., 1963). As the concentration of L-glutamic acid necessary for reversion of type 4 to type I covered a narrow range, this may be related to the iron content of the medium. This, however, was not determined.

The two factors, iron and an iron chelator, are essential for both the reversion of type 4 gonococci to type $\mathrm{I}$ and the prevention of the reversion of type 1 gonococci to type 4 . Although some chelators alone, e.g. sodium citrate, are sufficient to bring about these effects assisted by the trace of iron in the medium, those containing iron are superior, e.g. ferric citrate (Hafiz et al., I977) and ferric ammonium citrate. The iron chelators bind iron and the outcome of this could be either to make iron more readily available for bacterial iron assimilation or perhaps to limit iron availability. To date, there is no report that gonococci can form siderochromes (iron chelators), but as the present results indicate that iron chelators are involved in reverting gonococci type 4 to type $\mathbf{I}$, this could either mean that the iron chelators in this study provide more iron for type 4 gonococci, hence reversion to type $I$, or that the chelators withdraw iron from type 4 with reversion to type I under critical environmental conditions.

The authors thank Professor M. G. McEntegart, Department of Medical Microbiology and Dr Pauline Harrison, Biochemistry Department, University of Sheffield, for their useful suggestions during the course of the study. This work was supported by the Medical Research Council grant no. 4II7/08. Dr T. O. Odugbemi is supported by a study leave grant from the University of Lagos.

\section{REFERENCES}

Bullen, J. J., Rogers, N. J. \& GrifFiths, E. ( I974). Bacterial iron metabolism in infection and immunity. In Microbial Iron Metabolism, a Comprehensive Treatise, pp. 517-55I. Edited by J. B. Neilands. London and New York: Academic Press.

COLE, L. J. (1952). Suppression of colonial variation in Brucella abortus by metal-complexing compounds. Journal of Bacteriology 64, 847-853.

Hafiz, S. \& McEntegart, M. G. (1976). Prolonged survival of Neisseria gonorrhoeae in a new liquid medium. British Journal of Venereal Diseases $\mathbf{5 2}$, $38 \mathbf{I}-383$

Hafiz, S., McEntegart, M. G. \& JePhCotT, A. E. (1977). The reversibility in liquid media of Kellogg's colonial types of $N$. gonorrhoeae. Journal of Medical Microbiology ro, 377-380.
Hutner, S. H. (1972). Inorganic nutrition. Annual Review of Microbiology 26, 314-345.

JеPHCOTT, A. E. \& ReYN, A. (1971). Neisseria gonorrhoeae. Colony variation I. Acta pathologica et microbiologica scandinavica B 79, 609-6I4.

Kellogg, D. S., Jr, Peacock, W. L., Jr, Deacon, W. E., Brown, L. \& Pirkle, C. I. (I963). Neisseria gonorrhoeae. I. Virulence genetically linked to clonal variation. Journal of Bacteriology 85, $1274-$ I 279 .

Payne, S. M. \& Finkelstein, R. A. (1975). Pathogenesis and immunology of experimental gonococcal infection. Role of iron in virulence Infection and Immunity 12, I 3 I 3-1318. 